\section{ORDEM URBANA NAS METRÓPOLES BRASILEIRAS: ANÁLISE DA TRANSIÇÃO URBANA E DOS DESAFIOS METROPOLITANOS}

\author{
Marcelo Gomes Ribeiro*
}

A questão urbana no Brasil e seu corolário, a constituição das metrópoles, foram teorizados até os anos 1970 como decorrentes do processo de desenvolvimento econômico que o país experimentou no período de 1930 (1950) a 1980, baseado na política de substituição de importações, o que permitiu sua industrialização concentrada nos principais centros urbanos. Até aquele momento, foram produzidas variadas interpretações desse processo, abrangendo desde análises realizadas em nível nacional, por meio de estudos da rede urbana brasileira, até análises intraurbanas, em que se destacaram os estudos dos processos e mecanismos produtores da segregação urbana. As diversas interpretações mobilizaram diferentes vertentes teóricas, as principais delas de abordagem marxista, que tinham em comum a compreensão da questão urbana. Essa compreensão se colocava como problema teórico porque a realidade desafiava as formulações constituídas até aquele momento. Passados mais de três décadas, tendo em vista as transformações ocorridas no Brasil no período de 1980 a 2010, o livro Ordem urbana nas metrópoles brasileiras: análise da transição urbana e dos desafios metropolitanos (Ribeiro, 2017) não apenas reconstitui a discussão e as formulações teórico-interpretativas daquele momento, como, inspirado nelas, procura compreender a metrópole hoje, sua ordem urbana, dentro do quadro de transições demográficas, econômicas, políticas e sociais experimentados pelo país.
Trata-se de uma coletânea de textos elaborados em diferentes momentos, mas que constituem uma unidade teórico-conceitual. Tanto aqueles em que se procura formular as hipóteses analíticas quanto os que apresentam evidências das transformações das metrópoles brasileiras mobilizam o mesmo arcabouço teórico-interpretativo.

Os textos reunidos buscam apresentar uma interpretação abrangente da transição urbana brasileira no período de 1980 a 2010. É abrangente por quatro motivos: primeiro, pela preocupação com a realização de análise histórica, pois a compreensão da metrópole contemporânea requer o entendimento de sua constituição e das mudanças por que ela passou, e isso requereu resgatar a análise do período anterior a 1980 para a compreensão das mudanças nas décadas seguintes; segundo, a interpretação é abrangente metodologicamente porque a análise da metrópole necessita que sejam mobilizadas diversas áreas do conhecimento (Economia, Sociologia, Geografia, Ciência Política, Demografia, entre outras) e variadas temáticas que implicam seu entendimento (mercado de trabalho, estrutura produtiva, rede urbana, estrutura social, cultura política etc.), cada uma delas com princípios e procedimentos analíticos que lhe são próprios; terceiro, ela é abrangente também devido à escala de análise utilizada, pois houve também a preocupação de articular os macroprocessos sociais, econômicos, demográficos e políticos observados em nível mundial, nacional e regional, com a dinâmica observada no espaço intraurbano de cada metrópole brasileira, o que demonstra uma análise interescalar; e, por fim, é abrangente teoricamente, pois, pelos aspectos já mencionados - histórico, metodológico e escalar -, percebe-se a necessidade que teve de articulação de perspectivas teóricas específicas de cada área do conhecimento, sem cair na tentação de ecletismo teórico. E, nesse sentido, podemos considerar que foi bem sucedido o desafio de articulação de teorias das diferentes áreas do conhecimento que 
foram capazes de construir uma interpretação das metrópoles brasileiras, tendo em vista que há coerência em sua integração, tanto para os desafios da análise histórica quanto para os desafios metodológicos e escalares que se apresentaram. Para o sucesso dessa empreitada, podemos considerar que foi fundamental a construção do conceito de ordem urbana, pois sua formulação se pretendeu capaz de compreender a multiplicidade dos fenômenos articulados que se manifesta na cidade.

O livro é organizado em três partes: 1. "As metrópoles e a formação da ordem urbana"; 2. "As metrópoles e a transição urbana"; 3. "Os desafios metropolitanos". Darei aqui maior destaque à primeira parte, porque é onde é apresentado o conceito de ordem urbana. Para que essa formulação fosse realizada, o autor apresentou, inicialmente, um capítulo de caráter histórico-analítico, onde procurou demonstrar a constituição da questão urbana na sociedade brasileira, quando somente a partir dos anos 1980 os problemas urbanos foram integrados à questão social, substituindo as representações antiurbanas da fase anterior ("A cidade contra a Nação", "A cidade contra o Estado" e "A cidade contra o Nacional-desenvolvimentismo"), para representações que possibilitaram "coincidir a cidade com a cidadania", nos marcos do movimento da reforma urbana. Mas

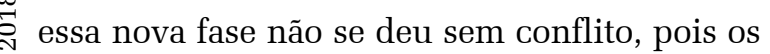
princípios da reforma urbana foram desafiados por uma agenda em que se requereu também $a$ cidade como máquina de crescimento: a cidade para o mercado, sob o prisma da competitividade local, foi por onde se passou a situar a disputa do urbano no Brasil.

No segundo capítulo, são apresentados os pressupostos teórico-históricos que fundamentam o conceito de ordem urbana. Segundo o autor, ao recuperar os trabalhos de Manuel Castells (1972), a ordem urbana deve ser compreendida como "a relação entre a cidade e a sociedade" entendidas "como fatos sócio-históricos e morfológicos”. Além disso, ao considerar a análise de Aníbal Quijano (1978) sobre a urbanização latino-americana, o autor procurou também sublinhar alguns aspectos relevantes para compreensão da ordem urbana brasileira: 1. é preciso pensá-la como fenômeno multidimensional; 2 . cada dimensão mantém relação de interdependência com as outras, mas cada uma possui, ao mesmo tempo, relativa autonomia; 3 . trata-se de sociedades dependentes, por isso a necessidade de compreender as relações de interdependência entre as sociedades (inseridas no sistema-mundo); 4. é um fenômeno estrutural-histórico, porque decorre das determinações das leis gerais do desenvolvimento capitalista, mas há expressões históricas concretas em que elas se manifestam que precisam ser consideradas. Para a compreensão da ordem urbana, portanto, "trata-se de ir além da sistemática descrição da dimensão ecológica-demográfica da organização territorial das metrópoles, buscando relacioná-la com algumas das importantes dimensões da estruturação e da reprodução da sociedade brasileira enquanto espaço social constituído por um padrão particular de desenvolvimento capitalista” (p. 138). Como se observa, a formulação da ordem urbana requer uma estratégia ousada de articulação entre sociedade e espaço, entre as diversas dimensões que recaem sobre aquela relação, entre diferentes escalas analíticas e, ao mesmo tempo, como fenômeno estrutural-histórico, tarefa que foi realizada ao longo do capítulo.

No terceiro capítulo, último da primeira parte do livro, o autor apresenta as características atuais das metrópoles brasileiras, situando-as dentro do processo de urbanização ocorrido, principalmente, a partir dos anos 1950. Para análise da fase atual, é definido o conceito de metrópole como aglomerados urbanos que concentram poder econômico, social e cultural e apresentam capacidade de polarização do território nas escalas nacionais, regionais e locais, o que se contrapõe à ideia de região metropolitana, pois ela decorre de institucionalização feita por meio de leis. É a partir disso que são feitas análises do processo de concen- 
tração e dispersão no interior de cada metrópole, tendo em vista que se consideram, por meio daquela definição, 15 aglomerados urbanos como metrópoles. O que se observa é que as periferias metropolitanas estão apresentando ritmo de crescimento maior que os núcleos metropolitanos, mas eles ainda se constituem como lugar de concentração populacional, inclusive apresentando um incremento absoluto de pessoas muito elevado. A consequência disso se coloca como um dos principais dramas metropolitanos da atualidade: a crise da mobilidade urbana, como é analisada ao final do capítulo.

A segunda parte é constituída pelos capítulos 4, 5 e 6. Como estes dois últimos ${ }_{1}$ se referem à aplicação do conceito de ordem urbana, discutida na primeira parte, e à estratégia metodológica apresentada no capítulo 4, darei maior ênfase à discussão apresentada nesse último capítulo mencionado. O capítulo 4 apresenta a estratégia metodológica que contribuiu para orientar as análises de transformação da ordem urbana de 14 metrópoles no país, constituindo-se como um empreendimento ambicioso de análise comparativa. Para tanto, o autor procurou situar essa estratégia a partir dos marcos do pensamento social brasileiro que se conformou entre as décadas de 1960 e 1970, mas que cedeu lugar ao debate internacional sobre a global city, a partir dos anos 1990, sobretudo no campo dos estudos urbanos. A estratégia metodológica consistiu em pensar as metrópoles a partir de três óticas da dinâmica territorial: "economia-território, sociedade-território e política-território". O foco da análise se deu na segunda ótica analítica: sociedade-território. Isso porque é com essa ótica que se busca compreender a organização social do território metropolitano, sendo, portanto, a variável dependente da análise realizada. A explicação dessa variável se dá por meio

${ }^{1}$ No capítulo 5, é feita a análise da transformação da ordem urbana na metrópole do Rio de Janeiro no período de 1980 a 2010; no capítulo 6, é analisada a cidade do Rio de Janeiro no contexto dos megaeventos - Copa do Mundo e Olimpíadas -, mobilizando-se o arcabouço teórico compreendido como economia política da urbanização. de dois conjuntos de variáveis independentes: variáveis referentes ao processo histórico de formação social, econômica e política de cada metrópole na urbanização ou metropolização brasileira; e variáveis em que se identificam os padrões e as dinâmicas de organização social do território de cada metrópole. A partir dessa compreensão, são discutidas também a relação entre aquela organização territorial e as desigualdades das condições urbanas e as desigualdades referentes à estrutura de oportunidades relacionadas à educação e ao trabalho. Essas análises permitem a realização de interpretações das transformações experimentadas por cada uma das metrópoles à luz da formulação da ordem urbana. Vale ressaltar também a preocupação apresentada no texto com a estratégia comparativa, tendo em vista que, no campo das Ciências Sociais, comparar não é uma operação trivial. Por isso, o autor apresenta quatro modelos de análises comparativas, a partir de análises realizadas no campo dos estudos urbanos: de caráter individualizado, universalizado, abrangente e variação-descoberta. De acordo com a estratégia metodológica escolhida para a realização de pesquisa em 14 metrópoles brasileiras, podemos considerar que a orientação adotada foi a utilização do modelo variação-descoberta de análise comparativa, tendo em vista que, nessa proposta metodológica, procura-se "estabelecer um princípio de variação no caráter e intensidade de um fenômeno mediante o exame das diferenças sistemáticas entre os papéis e entre as instâncias". Essa orientação também considera as variações induzidas por dinâmicas globais, nacionais, regionais e locais.

Na terceira parte do livro, constituída por quatro capítulos (7, 8, 9 e 10), são resgatados os pressupostos teóricos que orientaram a formulação do conceito de ordem urbana para a análise da governança metropolitana no Brasil, principalmente depois da promulgação do Estatuto das Metrópoles (capítulo 7). E ainda se promove: a análise e interpretação da cidade neoliberal na América Latina (capítulo 8); 
a realização de reflexões que permitem a formulação de uma teoria urbana do processo de metropolização latino-americano (capítulo 9); e elaboração de uma agenda de pesquisa orientada pelas esperanças e desafios observados na transição da ordem urbana das metrópoles brasileiras (capítulo 10).

Como cada capítulo foi escrito em situação distinta, de acordo com o que é mencionado em cada um deles, em muitos momentos, há uma sensação de repetição da abordagem teórica que fundamenta o conceito de ordem urbana e também da análise histórica de transformação das metrópoles brasileiras. No entanto, essa sensação é dirimida à medida que o conjunto das análises realizadas ganha unidade teórico-conceitual, principalmente em se tratando de uma pesquisa no campo das Ciências Sociais, em que o desafio teórico-metodológico se impõe com muita ênfase para a realização de pesquisa comparada. Isto é, a preocupação com a co- erência teórico-metodológica leva ao pecado da repetição.

A metrópole em questão é um livro que inova no campo das Ciências Sociais justamente pelos desafios de articulação de uma estratégica teórico-metodológica capaz de comparar contextos diferentes, articular diferentes escalas analíticas e, ao mesmo tempo, realizar análise histórica e estrutural de modo sistemático, o que permite a realização de uma interpretação abrangente das transformações da ordem urbana das metrópoles brasileiras. Por isso, sua leitura é altamente recomendada.

Recebido para publicação em 14 de setembro de 2017 Aceito em 14 de dezembro de 2017

\section{REFERÊNCIAS}

RIBEIRO, Luiz Cesar de Queiroz. A metrópole em questão: desafios da transição urbana. 1. ed. Rio de Janeiro: Letra Capital: Observatório das Metrópoles, 2017.

*Marcelo Gomes Ribeiro - Marcelo Gomes Ribeiro - Doutor em Planejamento Urbano e Regional pela Universidade Federal do Rio de Janeiro (UFRJ). Professor do Instituto de Pesquisa e Planejamento Urbano e Regional (IPPUR) da UFRJ. Vice-coordenador do Programa de Pós-graduação em Planejamento Urbano e Regional da UFRJ. Integra o Observatório das Metrópoles, desenvolvendo pesquisas na área de Economia Metropolitana, Desigualdades e Segregação Urbana. Instituto de Pesquisa e Planejamento Urbano e Regional (IPPUR), Universidade Federal do Rio de Janeiro (UFRJ). Av. Horácio Macedo, 2151, Cidade Universitária Ilha do Fundão - CEP: 21941-917- Rio de Janeiro - RJ - Brasil. marceloribeiro@ippur.ufrj.br 